\title{
USO DE PRÁTICAS INTEGRATIVAS E COMPLEMENTARES NO PACIENTE ONCOLÓGICO
}

\author{
Pedro de Sousa Leitel ${ }^{\text {, Italo Marcelo Maia Marques }}{ }^{l}$,Constantino Felipe Leandro Clementino ${ }^{l}$, \\ Wine Suélhi dos Santos ${ }^{2}$, Andrea Couto Feitosa ${ }^{3}$
}

Introdução: Atualmente, o câncer é uma das doenças que mais causa mortes no mundo, no qual a presença do impacto negativo da dor na qualidade de vida do paciente oncológico é o principal desafio encontrado. Diante disso, a necessidade de encontrar e estimular o uso de estratégias eficazes para diminuir essas sensações dolorosas é uma ferramenta de relevância no contexto da assistência. Sendo assim, a utilização de Praticas Integrativas e Complementares ( PICs) caracterizam como modelo essencial promovendo um sistema natural de prevenção, controle terapêutico e de cura na população, destacando o paciente com câncer. Objetivo: Identificar principais PICs utilizadas no paciente oncológico, descrever benefícios no cuidado do paciente e indicar justificativas do uso das PICs. Método: Revisão sistemática com abordagem qualitativa segundo as recomendações do protocolo PRISMA. As bases de dados pesquisadas foram SciELO, LILACS, ScienceDirect, Cochrane Library, MEDLINE/PubMed e The Lancet com uso dos descritores em DeCS Terapias Complementares, paciente e oncológico.Foram selecionadas publicações de 2013 a 2018, em qualquer idioma, e completos. Foram excluídos estudos inconclusivos, com baixo teor metodológico ou com alto risco de viés. Resultados: Identificaram-se 1980 estudos , dos quais apenas 20 cumpriram aos critérios e foram incluídos. As principais PICs utilizadas são a fitoterapia e intervenções mente-corpo, como a oração de cura. Apresentam como benefícios ao paciente oncológico: fortalecimento do sistema imune, diminuição de sinais e sintomas da enfermidade, promove melhoria na qualidade de vida e influencia no seguimento do tratamento convencional. Como justificativa ao seu uso, destaca-se a insatisfação diante da medicina convencional, a possibilidade de auto-cuidado e a possibilidade de minimização dos efeitos colaterais. Conclusão: Portanto torna-se evidente o aumento do seu uso no cenário clinico atual, possibilitando novas intervenções no paciente oncológico, consequentemente facilitando a introdução do auto-cuidado e melhorias na qualidade de vida. Entretanto, é notória a carência de estudos que promovam seu uso pela equipe multiprofissional.

Palavras- Chave: Terapias Complementares, paciente e oncológico

\footnotetext{
${ }^{1}$ Discentes do Curso de Medicina da Faculdade de Medicina de Juazeiro do Norte- Estácio FMJ;

${ }^{2}$ Residente em Terapia Intensiva no Hospital Dom Hélder Câmara;

${ }^{3}$ Docente do Curso de Enfermagem do Centro Universitário Leão Sampaio;

Autor correspondente: pedroed1913@hotmail.com
}

39 Id on Line Rev. Mult. Psic. V.12, N. 40. 2018 - ISSN 1981-1179 EDIÇÃO ESPECIAL: I CURSO DE ONCOLOGIA DO CARIRI / II JORNADA DE PESQUISA QUANTI-QUALITATIVA EM ONCOLOGIA. JUAZEIRO DO NORTE, 05 A 10 DE MARÇO DE 2018. Edição eletrônica em http://idonline.emnuvens.com.br/id 